\title{
Occupational lead exposure and blood pressure
}

\author{
D K PARKINSON, ${ }^{1}$ M J HODGSON, ${ }^{1}$ EVELYN J BROMET, ${ }^{2}$ \\ MARY AMANDA DEW, ${ }^{2}$ MELANIE M CONNELL, ${ }^{2}$
} From the Departments of Medicine, ${ }^{1}$ and Psychiatry, ${ }^{2}$ University of Pittsburgh, Pittsburgh, Pennsylvania, US Âे

ABSTRACT Recent community studies have suggested that low level lead exposure is significantly associated with blood pressure in the general population. This finding is inconsistent with the resulf of recent occupational studies of lead exposed workers, although the occupational studies containe serious methodological weaknesses. The present study examined the relation between occupationa lead exposure and diastolic and systolic blood pressure in randomly selected samples of 270 expose $\$$ and 158 non-exposed workers. Four exposure indicators were examined: employment at a leadt battery plant $v$ a control plant, current blood lead value, current zinc protoporphyrin value, and time weighted average blood lead value. After controlling for other known risk factors such as ages education, income, cigarette usage, alcohol consumption, and exercise, the associations between exposure and blood pressure were small and non-significant. In the absence of a biologically feasible hypothesis regarding the mechanism by which low level lead exposure would influence blood prese sure the present findings challenge the validity of the general population association.

The relation between lead exposure and rises in blood pressure has recently received a great deal of attention because of the implication that mortality from cardiovascular and cerebrovascular disease might be reduced by lowering lead values in the environment. ${ }^{1}$ Early reports focused on workers in the lead industries and described hypertension and nephritis as frequent manifestations of lead exposure. ${ }^{23}$ More recently, Dingwall-Fordyce and Lane showed an excess mortality from cerebrovascular disease in lead exposed workers with 25 years of exposure occurring before 1961.4 The excess mortality was greater for workers dying between 1926 and 1950 than for workers dying between 1951 and 1961. With one exception $^{5}$ studies conducted since the classic research of Dingwall-Fordyce and Lane have confirmed the original findings. ${ }^{6-9}$ It should be noted that these studies were conducted in plants with extremely high levels of exposure to lead, and the study that failed to find an excess in mortality ${ }^{5}$ was conducted after exposure had been substantially reduced. Because of these extremely high exposures and the almost inevitable nephrotoxicity, the most parsimonious explanation of the excess cardiovascular and cerebrovascular mortality is hypertension secondary to renal disease rather than primary hypertension.

Two studies have directly examined the relation

Accepted 20 October 1986 between occupational lead exposure and blood presero sure. $^{1011}$ Cramer and Dahlberg classified 364 long term employees of a storage battery plant into a "lead" affected" group (those having a measurable urinarg coproporphyrin level since employment at the plant and a "lead unaffected" group. ${ }^{10}$ No significand difference in the rate of hypertension in the two groups was found. In the second study Ramirez Cervantes et al stratified 652 lead smelter workers with at least five years of exposure into a group with current blood lead values exceeding $60 \mu \mathrm{g} / 100 \mathrm{ml}$ 萨 those with lower current blood lead values. ${ }^{11}$ They found no differences in systolic and diastolic bloo pressure. Both studies, however, have serious flaw with respect to the measurement of lead exposure and blood pressure. Specifically, urinary coproporphyrim. values are known to have little correlation wit $\$$ current blood lead values. In the Ramirez-Cervantes study lead values and blood pressure were not deterg mined simultaneously. In neither study was the tech nique for determining blood pressure described, no․ were known predictors of blood pressure, such as age and obesity, considered in the analysis.

The discordance between findings of a positivg relation between blood lead values and blood pres sure in the general population ${ }^{12-15}$ and the lack of association in occupational studies, where exposures levels were higher, suggested the need to re-evaluat whether occupational lead exposure at present da $\%$ levels is associated with increased blood pressure. The 
present study was designed to examine whether higher levels of current, recent, and cumulative lead exposure are systematically associated with increases in blood pressure in a randomly selected sample of lead exposed and non-exposed workers. To overcome the methodological problems described above, the study included standardised blood pressure measurements, direct measures of exposure, and careful assessments of other known predictors of blood pressure.

\section{Methods}

\section{SA M PLE}

The present study was based on data collected in 1982 in eastern Pennsylvania from 288 lead exposed workers recruited from three battery plants and 181 nonexposed workers from a truck side frame manufacturing plant with no known neurotoxic exposures, such as lead, arsenic, or solvents. All four plants were organised by the United Steel Workers of America. The workers participating in the study were white, native English speaking men aged 18-60, and employed at the plant for at least one year. ${ }^{16}$

The subjects were drawn from company listings containing name, address, telephone number, age, and, for workers in the battery plants, the most recent blood lead value. To examine a range of cumulative exposure levels, we increased the proportion of older workers with longer term exposure by stratifying workers in each plant into three age groups (18-25; $26-30 ; 31-60)$, and drawing proportionate random samples of $10 \%, 30 \%$, and $60 \%$, respectively. Refusal rates were $32 \%$ among exposed and $33 \%$ among nonexposed workers. Comparisons between participants and refusers from the lead battery plants showed no differences in their most recent blood lead values. In one lead plant, and in the control plant, refusers were somewhat older than participants. In addition, $6 \cdot 2 \%$ of the lead exposed workers and $12.7 \%$ of the controls were taking antihypertensive medication and were therefore excluded from the present analysis. Since the study was considering the effects of lead exposure on blood pressure, the inclusion of known hypertensive subjects whose blood pressure had been controlled by treatment would have obscured the potential relation of interest. The finding of a higher proportion of comparison workers taking antihypertensive agents probably reflects the somewhat older mean age of the comparison workers. The present analysis was thus conducted using 428 workers ( 270 exposed and 158 non-exposed).

\section{DATA COLLECTION}

Subjects were examined before work or during the weekend in an office maintained for the study. Blood pressure was measured three times, at five minute intervals, with the worker sitting. The first and fourth Korotkoff sounds were used as indicators of systolic and diastolic blood pressure, respectively. Three medical technicians were trained by the senior author (DKP). Analyses conducted to determine potential interrater variability indicated no systematic differences among the technicians.

Blood lead values were determined using atomic absorption spectophotometry laboratories certified by the Occupational Safety and Health Administration. In the analyses four measures of lead exposure were considered: (a) employment at the lead exposure $v$ control plant; $(b)$ current blood lead values at the time of examination; (c) zinc protoporhyrin values at the time of examination; and (d) time weighted average (TWA) blood lead values (a cumulative index derived for the lead exposed workers from all blood lead values since date of hire taken by the lead battery companies). It should be noted that the TWA $^{17}$ was not calculated for 12 workers with fewer than four recorded blood lead values because of concerns about reliability. The median number of blood lead values was 14 , and in 40 workers blood lead values had been determined on more than 60 occasions.

To control for other known risk factors, the following variables were included in the analyses: age; years of education; total family income, alcohol use (average number of drinks a day), a quantitative measure of current cigarette usage, level of exercise and body mass index (weight divided by height squared). These variables are defined in detail in table 1 .

\section{DATA ANALYSIS}

The relation between blood lead and blood pressure was first examined by determining the zero order correlations between blood lead and blood pressure. Next, multiple linear regression models were constructed for systolic and diastolic blood pressure. In these models known predictors of blood pressure were initially placed in the regression equation-age, education, income, alcohol use, smoking, exercise, and body mass index. A single exposure index was then added to the equation to determine its predictive power over and above these known predictors. This procedure was repeated with each of the four exposure variables: employment at the exposure $v$ control plant, current blood lead values, zinc protoporphyrin (natural logarithm), and TWA blood lead value (for the lead workers alone). Thus eight models, four each for systolic and diastolic blood pressure, were examined. It should be noted that multicollinearity was not a problem in this data set since the predictors were not highly intercorrelated (see results below). 
Table 1 Means and standard deviations of all study variables

\begin{tabular}{|c|c|c|c|c|}
\hline \multirow[b]{2}{*}{ Variables } & \multicolumn{2}{|c|}{ Lead workers $(n=270)$} & \multicolumn{2}{|c|}{ Control workers $(n=158)$} \\
\hline & Mean & $S D$ & Mean & $S D$ \\
\hline $\begin{array}{l}\text { Age } \\
\text { Body mass index } \\
\text { Alcohol } \\
\text { Exercise } † \\
\text { Current cigarette use† } \\
\text { Education } \\
\text { Income } \\
\text { Current blood lead } \\
\text { Zinc protoporphyrins } \\
\text { Time weight and lead average } \\
\text { Systolic BP } \\
\text { Diastolic BP }\end{array}$ & $\begin{array}{r}34 \cdot 8 \\
26 \cdot 5 \\
1 \cdot 7 \\
1 \cdot 7 \\
1 \cdot 7 \\
11 \cdot 1 \\
5 \cdot 1 \\
39 \cdot 9 \\
89 \cdot 9 \\
48 \cdot 8 \\
126 \cdot 5 \\
79 \cdot 0\end{array}$ & $\begin{array}{l}10 \cdot 1 \dagger \\
4 \cdot 8 \\
2 \cdot 5 \\
1 \cdot 5 \\
1 \cdot 7 \\
1 \cdot 7^{*} \\
1 \cdot 4^{* *} \\
13 \cdot 2^{* *} \\
67 \cdot 1^{* *} \\
11 \cdot 9 \\
13 \cdot 4 \\
10 \cdot 5\end{array}$ & $\begin{array}{c}38 \cdot 6 \\
26.6 \\
1.6 \\
1.9 \\
1.4 \\
11 \cdot 5 \\
6 \cdot 6 \\
7.4 \\
30 \cdot 3 \\
\text { N/A } \\
129 \cdot 0 \\
80.8\end{array}$ & $\begin{array}{r}11 \cdot 0 \\
4 \cdot 5 \\
2 \cdot 4 \\
1 \cdot 6 \\
1 \cdot 7 \\
1 \cdot 7 \\
1 \cdot 2 \\
4 \cdot 7 \\
7 \cdot 5 \\
\text { N/A } \\
15 \cdot 1 \\
11 \cdot 0\end{array}$ \\
\hline
\end{tabular}

$* \mathrm{p}<0.05 ; *$ p $<0.001$.

+Coded as: $1=$ never; $2=<$ once/week; $3=$ once or twice/week; $4=3-4 /$ week; $5=$ nearly every day.

+ Coded as: $1=$ none; $2=$ occasionally; $3=1-10 /$ day; $4=11-20 /$ day; $5=>20 /$ day;.

$\$$ Coded as: $1=<\$ 5000 ; 2=\$ 5000-9999 ; 3=\$ 10000-14999 ; 4=\$ 15000-19999 ; 5=\$ 20000-24999 ; 6=\$ 25000-29999 ;$

$7=\$ 30000-34999 ; 8=>\$ 35000$.

\section{Results}

Table 1 shows the means and standard deviations for the lead control workers for all the variables considered in this study. The control workers were significantly older, had higher incomes, and were slightly better educated than the lead workers. As expected, the lead workers had significantly higher blood lead and zinc protoporphyrin values. The two groups of workers did not differ significantly on mean systolic or diastolic blood pressure or on the major risk factors associated with hypertension (current alcohol use, cigarette use, exercise, and body mass index).

The zero order correlations among blood pressure, lead exposure, and the hypertension risk factors are presented in table 2 for the combined sample of lead and control workers. Of the three exposure measures $z$ only the TWA blood lead was significantly, albeif modestly, correlated with blood pressure. This vari 3 able was also significantly related to body mass index and exercise. Most of the exposure variables were significantly correlated with age, income, and e\&u cation. Finally, the blood pressure measurements were significantly correlated with age, body mầ. index, and alcohol consumption, although thes showed little relation to the other risk factors (cigao rette use, amount of exercise) or to the measures of socioeconomic status (education, income).

Tables 3 and 4 present the results of the multiplet regression analyses in which diastolic and systolig blood pressure served as the dependent variables. As

Table 2 Intercorrelation among blood pressure, exposure, and risk factors for all lead and control workers combined ( $n=428$ )

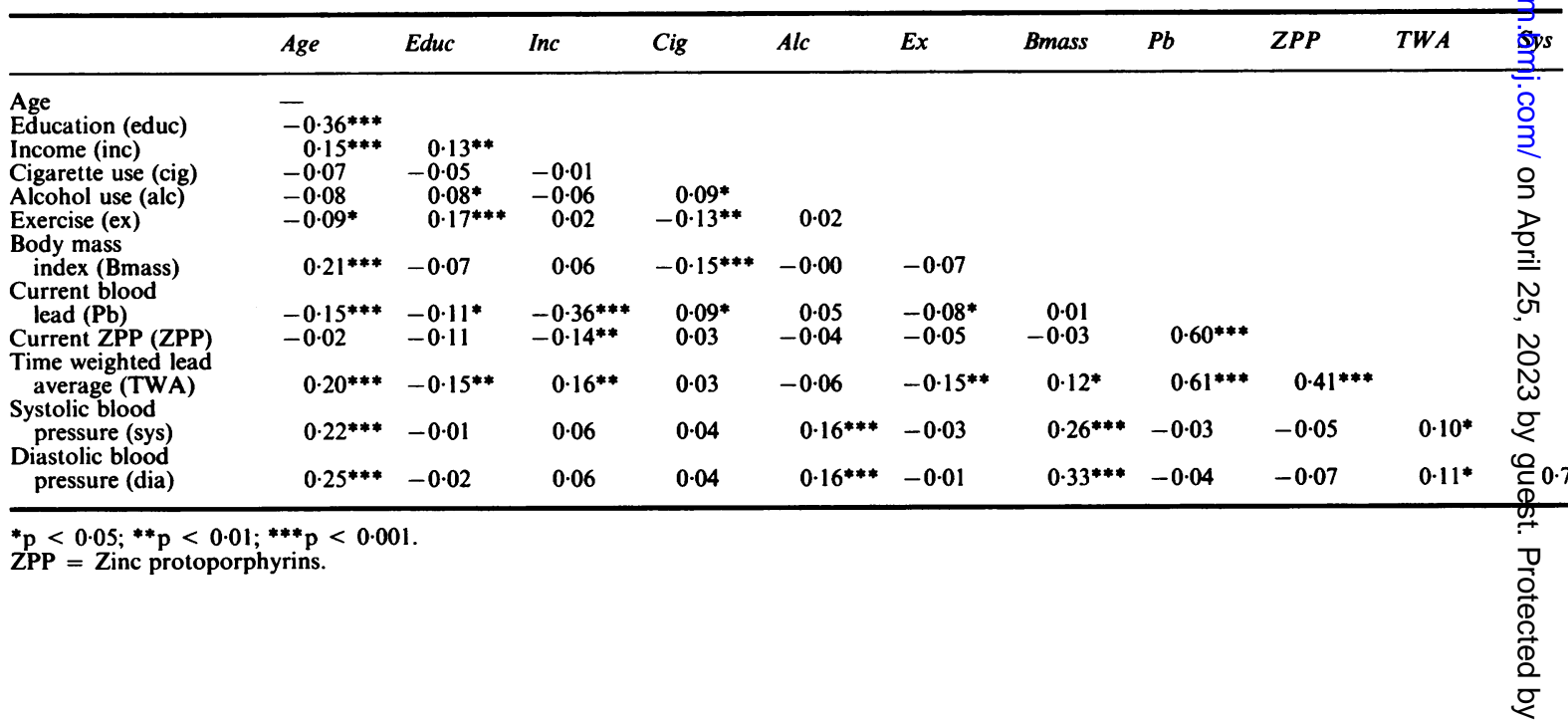


Table 3 Multiple regresssion of diastolic blood pressure on lead exposure controlling for seven risk factors: standardised regression coefficients

\begin{tabular}{|c|c|c|c|c|}
\hline \multirow[b]{2}{*}{ Variable } & \multicolumn{4}{|c|}{ Exposure variables } \\
\hline & $\begin{array}{l}\text { Lead } v \text { control } \\
\text { beta } \\
(n=399)\end{array}$ & $\begin{array}{l}\text { Current blood lead } \\
\text { beta } \\
(n=389)\end{array}$ & $\begin{array}{l}\text { Zinc protophorphyrins } \dagger \\
\text { beta } \\
(n=387)\end{array}$ & $\begin{array}{l}\text { TWA for lead+ } \\
\text { beta } \\
(n=246)\end{array}$ \\
\hline $\begin{array}{l}\text { Age } \\
\text { Education } \\
\text { Income } \\
\text { Cigarette use } \\
\text { Alcohol use } \\
\text { Exercise } \\
\text { Body mass } \\
\text { Exposure variable } \\
\mathbf{R}^{\mathbf{2}}\end{array}$ & $\begin{array}{l}0.239^{* *} \\
0.078 \\
-0.016 \\
0.089 \\
0 \cdot 169^{* *} \\
0.020 \\
0.303^{* *} \\
-0.029 \\
0.19\end{array}$ & $\begin{array}{l}0.245^{* *} \\
0.080 \\
-0.015 \\
0.080 \\
0.182 \dagger \\
0.031 \\
0.296^{* *} \\
-0.003 \\
0.19\end{array}$ & $\begin{array}{l}0.242^{* *} \\
0.076 \\
-0.019 \\
0.077 \\
0.172 \dagger \\
0.029 \\
0.290^{* *} \\
-0.024 \\
0.18\end{array}$ & $\begin{array}{l}0.115 \\
0.079 \\
-0.015 \\
0.084 \\
0.144^{*} \\
0.010 \\
0.305^{* *} \\
0.070 \\
0.14\end{array}$ \\
\hline
\end{tabular}

${ }^{*} \mathrm{p}<0.05 ;{ }^{* *} \mathrm{p}<0.001$.

†inc protoporphyrins analysed on a natural logarith scale.

$\ddagger$ Time weighted average for blood lead calculated for lead workers only.

may be seen, there were no statistically significant effects of employment status. Moreover, in separate analyses of lead and control workers, the regression coefficients for the risk factors were similar to those presented in column 1 . None of the quantitative exposure indices (columns 2-4) made a significant contribution in these models, and the size of the regression coefficients was uniformly small. On the other hand, age, body mass index, and alcohol consumption were significant predictors of blood pressure, with the risk factors explaining $14-19 \%$ of the variance in diastolic blood pressure and $9-15 \%$ of the variance in systolic blood pressure.

\section{Discussion}

The present study showed only small and statistically non-significant associations between occupational lead exposure and systolic or diastolic blood pressure. As expected, however, age, alcohol use, and body mass index were all relatively important predictors of both systolic and diastolic blood pressure. Thus the present findings are consistent with the results of the two earlier occupational studies. ${ }^{10-11}$

Before controlling for other predictors, there was a significant zero order relation between the TWA lead exposure and blood pressure. TWA, however, was significantly associated with age since older workers had been employed for a longer time in higher exposure conditions than younger workers. Thus once age was taken into account in the analysis, the effect of TWA on blood pressure was no longer significant.

Previous research on cerebrovascular mortality under conditions of high exposure suggested that renal damage was the aetiological factor in lead asso-

Table 4 Multiple regresssion of systolic blood pressure on lead exposure controlling for seven risk factors: standardised regression coefficients

\begin{tabular}{|c|c|c|c|c|}
\hline \multirow[b]{2}{*}{ Variable } & \multicolumn{4}{|c|}{ Exposure variables } \\
\hline & $\begin{array}{l}\text { Lead } v \text { control } \\
\text { beta } \\
(n=399)\end{array}$ & $\begin{array}{l}\text { Current blood lead } \\
\text { beta } \\
(n=389)\end{array}$ & $\begin{array}{l}\text { Zinc protophorphyrinst } \\
\text { beta } \\
(n=387)\end{array}$ & $\begin{array}{l}T W A \text { for leadt } \\
\text { beta } \\
(n=246)\end{array}$ \\
\hline $\begin{array}{l}\text { Age } \\
\text { Education } \\
\text { Income } \\
\text { Cigarette use } \\
\text { Alcohol use } \\
\text { Exercise } \\
\text { Body mass } \\
\text { Exposure variable } \\
\mathbf{R}^{\mathbf{2}}\end{array}$ & $\begin{array}{l}0.208^{* * *} \\
0.059 \\
-0.012 \\
0.081 \\
0.185^{* * *} \\
-0.006 \\
0.238^{* * *} \\
-0.051 \\
0.15\end{array}$ & $\begin{array}{l}0.215^{* * *} \\
0.063 \\
-0.018 \\
0.079 \\
0.197^{* * *} \\
0.011 \\
0.242^{* * *} \\
-0.009 \\
0.15\end{array}$ & $\begin{array}{l}0.219^{* * *} \\
0.063 \\
-0.012 \\
0.079 \\
0.187^{* * *} \\
0.012 \\
0.235^{* * *} \\
-0.018 \\
0.14\end{array}$ & $\begin{array}{l}0.037 \\
-0.006 \\
-0.027 \\
0.072 \\
0.194^{* *} \\
0.003 \\
0.203^{* *} \\
0.081 \\
0.09\end{array}$ \\
\hline
\end{tabular}

${ }^{*} \mathrm{p}<0.05 ;{ }^{* *} \mathrm{p}<0.01{ }^{* * *} \mathrm{p}<0.001$.

†Zinc protoporphyrins analysed on a natural logarith scale.

$\ddagger$ Time weighted average for blood lead calculated for lead workers only. 
ciated hypertension. ${ }^{61819}$ In our cohort there was no evidence of renal disease based on determination of serum creatinine or BUN levels. In fact, even the workers on antihypertensive medication who were not included in the analysis showed no evidence of altered renal function, although these indicators are admittedly insensitive to minor degrees of renal impairment. ${ }^{20}$ Other recent studies have also shown that kidney disease does not occur at currently mandated levels of occupational lead exposure. ${ }^{2122}$ In its absence there is no accepted pathophysiological mechanism by which blood lead would raise blood pressure. In fact, in workers with lead toxicity or overexposure decreased plasma renin response to salt deprivation and even hyporeninaemic hypoaldosteronism have been reported. ${ }^{2324}$ Thus the recent community studies reporting a significant association between low level lead exposure and blood pressure $^{11314}$ are difficult to interpret unless one invokes a separate mechanism operative only at low lead values.

Even in community studies showing significant associations the size of the observed effects is small and, as Pocock et al $^{12}$ stated with regard to their own findings: "In large scale surveys... it is the magnitude of an association, not its [statistical] significance, that is biologically important." 12 Thus it is conceivable that the findings from the community studies, which have large samples, have been overinterpreted. A recent editorial pointed out that in addition to the lead association, ${ }^{25}$ Pirkle et al also found significant and sometimes stronger relations between blood pressure and haemoglobin, serum albumin, dietary vitamin $\mathbf{C}$, potassium, riboflavin, and oleic acid. ${ }^{1} \mathbf{A}$ reanalysis of the data used by Pirkle et al found no association with blood lead value. ${ }^{26}$ Our investigation, in which a broader range of lead exposure was present, detected no significant effects. These negative results are consistent with the fact that there are no plausible biological hypotheses that could explain the effects of lead exposure in the absence of renal disease.

This project was supported by Grant MH 36221 from the National Institute of Mental Health and the National Institute of Occupational Safety and Health. We thank the United Steelworkers of America District 7 for their help with the study.

\section{References}

I Pirkle JL, Schwartz J, Landis JR, Harlan WR. The relationship between blood lead levels and blood pressure and its cardio- vascular risk implications. Am J Epidemiol 1985;121:246-58. $\bar{\zeta}$

2 Legge TM, Goadby KW. Lead poisoning and lead absorption London: Edward Arnold, 1912.

3 Lane RE. The care of the lead workers. $B r J$ Ind Meas. 1949;6:125-43.

4 Dingwall-Fordyce I, Lane RE. A follow-up study of lead work므 ers. Br J Ind Med 1963;20:313-5. 5 Malcolm D, Barnett HAR. A mortality study of lead workers. $B \frac{\bar{E}}{J}$

6 Cooper WC, Gaffey WR. Mortality of lead workers. J Occup Med 1975;17:100-7.

7 Selevan SG, Landrigan PJ, Stern PJ, Jones JH. Mortality of lead smelter workers. Am J Epidemiol 1985;122:673-83.

8 McMichael AJ, Johnson HM. Long-term mortality profile of heavily-exposed lead smelter workers. $J$ Occup Me屯 1982;24:375-8.

9 Davies JM. Long term mortality study of chromate pigmenD workers who suffered lead poisoning. $\mathrm{Br} J$ Ind Med 1984;41:170-8

10 Cramer K, Dahlberg L. Incidence of hypertension among leads workers. Br J Ind Med 1966;23:101-4.

11 Ramirez-Cervantes B, Embree TW, Hine CW, et al. Health $\vec{\overrightarrow{ }}$ assessment of employees with different body burdens of lead. J Occup Med 1978;20:610-9.

12 Pocock SJ, Shaper AG, Ashby D, Delves T, Whitehead TPO Blood lead concentration, blood pressure, and renal function. Br Med J 1984;289:872-4.

13 Orsaud G, Claude JR, Moreau T, Lellouch J, Juguet B, Festy B $\mathbf{Z}$ Blood lead concentration and blood pressure. Br Med 1985;290:244.

14 Harlan WR, Landis JR, Schmouder RL, Goldstein NG: Harlan CL. Blood lead and blood pressure: relationship in the adolescent and adult US population. JAMA 1985;253:530-4. $\overrightarrow{0}$

15 Beevers DG, Erskine E, Robertson M, et al. Blood lead 영 hypertension. Lancet 1976;ii:1-3.

16 Parkinson D, Ryan C, Bromet E, Connell M. A psychiafriq epidemiologic study of occupational lead exposure. A P Epidemiol 1986;123:435-40.

17 Haenninen H, Hernberg S, Mantere P, et al. Psychological per formance of subjects with low exposure to lead. J Occup Med 1978;20:683-9.

18 Emmerson BT. Chronic lead nephropathy. Kidney In $\stackrel{\mathbb{R}}{\mathscr{R}}$ 1973;4:1-5.

19 Batuman V, Landy E, Maeska JK, et al. Contribution of lead to응 hypertension with renal impairment. N Engl J Med 1983;309:17-21.

20 Hong CD, Hanenson IB, Lerner S, Hammond PB, Pesce AJ Pollak VE. Occupational exposure to lead: effects on renab function. Kidney Int 1980;18:489-94.

21 Greenberg A, Parkinson DK, Fetterolf DE, et al. Effects of elevated lead and cadmium burdens on renal function and calo cium metabolism. Arch Environ Health 1986;41:69-76.

22 Buchet JP, Roels H, Bernand A, Lauwerys R. Assessment of renal function of workers simultaneously exposed to inorganic lead and calcium. J Occup Med 1981;23:348-52.

23 Sandstead HH, Michelakis AM, Temple TE. Lead intoxication? its effect on the renin-aldosterone response to salt deprivation Arch Environ Health 1970;20:356-63.

24 Gonzalez JJ, Werk EE, Thrasher K, Behar R, Loadholt CB三. Renin aldosterone system and potassium levels in chronic lead intoxication. South Med J 1979;72:432-6.

25 Shaper AG, Pocock SJ. Blood lead and blood pressure. Br Med N 1985;291:1147-9.

26 Gartside P. Am J Epidemiol (in press). 